\title{
Construcciones perifrásticas en el castellano de los indígenas bilingües ashaninka-castellano de la selva central del Perú
}

\author{
Pedro Falcón Ccenta \\ Universidad Nacional Mayor de San Marcos \\ pfalconc17@gmail.com
}

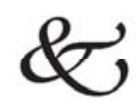

Resumen

\begin{abstract}
Se describen y analizan las diferentes construcciones perifrásticas del castellano de los indígenas bilingües ashaninka de la selva central. Se caracteriza el mayor uso de formas perifrásticas en el castellano de las mujeres indígenas bilinguies respecto de los varones, así como la mayor tendencia al uso de perífrasis verbales (PV) en personas con bajo grado de instrucción. Cabe mencionar que la producción perifrástica del castellano de este sector de la población es más bien limitada en cuanto a variedad y complejidad. Su productividad y frecuencia se centra en las formas 'ir + prep $(\varnothing)+$ infinitivo' o 'estar + gerundio'.
\end{abstract}

Palabras claves: Construcciones, perifrásticas, castellano, bilinguies amazónicos, Perú.

\begin{abstract}
The different periphrastic constructions of the Spanish spoken by bilingual indigenous ashaninka from the central rainforest area is described and analyzed. The more frequent use of periphrastic forms of the Spanish spoken by women compared to men is characterized, as well as the larger productivity of verbal periphrasis in people with low level of instruction. It is important to mention that the periphrastic construction of the Spanish spoken by people with elementary instruction is rather limited in terms of variety and complexity. Their productivity and frequency is focused on the forms 'go + prep (ø) + infinitive' or 'verb to be + gerund'. Key words: Periphrastic constructions, spanish, bilingual, amazonian people, Perú.
\end{abstract}




\section{Introducción}

La investigación describe y analiza las construcciones perifrásticas del castellano de los indígenas bilingüies de los grupos más importantes de la amazonía peruana desde la perspectiva demográfica, vale decir, los ashaninka, shipibo y awajún; sin embargo, por razones de espacio, se presentan las perífrasis verbales y algunas construcciones perifrásticas discutibles recogidas de 59 colaboradores de las comunidades nativas ashaninka y nomatsiguenga de las provincias de Chanchamayo y Satipo, departamento de Junín. Se entrevistaron a 31 hombres y 28 mujeres; 46 de ellos del grupo indígena ashaninka y 13 del grupo nomatsiguenga.

Los datos sujetos al análisis están basados en conversaciones, entrevistas grabadas (más de seis horas) semidirigidas y libres, pruebas formales complementarias y observación participativa.

El estudio procuró que el número de individuos sea proporcional a las comunidades visitadas de Chanchamayo y Satipo. En la muestra se encuentran representados colaboradores de ambos sexos agrupados por edades de 16 a 25 años, de 26 a 35 años y más de 36 años. Se consideraron dos niveles de escolaridad: primaria y secundaria.

La descripción de las diferentes estructuras perifrásticas correlacionadas con variables inherentes al individuo (sexo) y adscritas (escolaridad) se sustenta en las siguientes hipótesis:

Existe mayor incidencia en el uso de formas perifrásticas en las mujeres indígenas bilingüies amazónicas que en los hombres.

Las personas bilingües indígenas amazónicas con bajo nivel de instrucción son más proclives al uso de formas perifrásticas respecto de los que tienen un nivel mayor de instrucción.

Se evaluó cuantitativamente el uso de cada tipo de construcciones perifrásticas, sin dejar de lado algunas cuya clasificación está en discusión. Se registró cuantitativamente el uso de perífrasis de infinitivo, gerundio y participio según las variables mencionadas de edad, sexo y grado de instrucción; por ello, la descripción de las diferentes estructuras de construcciones perifrásticas de esta variedad del castellano se correlacionó con variables inherentes y adscritas.

No se revisan las teorías respecto a cuáles estructuras son consideradas perífrasis y cuáles no debido al carácter práctico del trabajo. Sin embargo, de las diferentes teorías se desprenden criterios esenciales respecto al concepto básico de las perífrasis verbales; en particular, desde la perspectiva funcional se han seguido algunos criterios vinculados a la identificación de PV basados en criterios semánticos, morfológicos y sintáctico-semánticos. 
Hay que tener en consideración que la producción perifrástica del castellano de los indígenas bilinguies de la selva central, en términos generales, no es rica en cuanto a variedad ni complejidad. La productividad y frecuencia se centra en las formas 'ir + prep $(\varnothing)+$ infinitivo' o 'estar + gerundio', que son usuales en el castellano. Estas formas, sobre todo la primera, evidencian en muchos casos procesos de elisión de la preposición (por ejemplo: voy (ø) bañar).

Si bien los indígenas bilingües utilizan recurrentemente construcciones perifrásticas, estas giran en torno a un número limitado de estructuras y en especial las mujeres centran su producción perifrástica en formas aspectuales 'estar + gerundio' o 'ir a + infinitivo'. Así mismo, existe una relativa mayor complejidad en construcciones perifrásticas producidas por indígenas bilinguies con mayor grado de instrucción.

Si bien las teorías y tratamientos del estudio han sido diversos, partimos del concepto de que la PV está vinculada al verbo auxiliar y a la auxiliaridad, pues en menor o mayor grado sirve de respaldo sintáctico-semántico al verbo principal. De esta manera, el verbo auxiliar se encuentra en estrecha relación con el concepto de gramaticalización.

En el caso de los modales se describen las construcciones estructuradas como 'deber + infinitivo' y 'poder + infinitivo'. En el caso de los aspectuales se evalúa la producción de variedades estructurales, cuyo registro en relación con los modales es mayor, pues a partir del corpus evaluado se identifican seis estructuras diferentes y las de mayor aparición son las formas 'estar + gerundio' e 'ir (prep) + infinitivo'. La mayor producción se evaluó sobre todo cuantitativamente con las variables de sexo y grado de instrucción.

\section{Concepto y clasificación de las perífrasis verbales}

Si bien se dice que toda forma verbal compuesta es ya perifrástica, se suele reservar el nombre de PV a las formadas por los verbos auxiliares que no están gramaticalizados internamente (ir, venir, deber, etc.). Con el infinitivo, el gerundio o el participio se destacan la expresión del aspecto o el desarrollo de la acción y de algunos de sus modos especiales. Se entiende también que la PV es una combinación de por lo menos dos unidades linguiísticas autónomas que de un modo determinado forman una unidad sintáctico-semántica.

Siguiendo a E. Coseriu (1), los verbos como acabar, andar, continuar, encontrarse, entrar, estar, hallarse, ir, ponerse, quedar, quedarse, resultar, salir, seguir, tornarse, venir, verse y volverse con gerundio o proposición más infinitivo son elementos de PV en el sentido de que, además de asumir morfemas, son modificadores gramaticales de los verbos en gerundio o infinitivo con los que se hallan construidos. 


\section{Pedro Falcón Ccenta}

Hernández (2) prefiere el término 'frases verbales', que define como sintagmas compuestos de un verbo desemantizado y conjugado. La preferencia, en términos de Rafael Seco (3), del uso de frases verbales se correlaciona con las frases sustantivas, adverbiales, prepositivas y conjuntivas, y evita menos equívocos que la de conjugación perifrástica.

Por otro lado, Roca-Pons (4), señala que la PV, entendida como la unión de un verbo auxiliar con una forma nominal de un verbo conceptual, presenta diferentes matices. En palabras del mencionado autor: "La lengua española es singularmente rica en combinaciones de esta clase, que sirven, como en otras lenguas, para expresar diversos matices temporales, aspectuales, modales, afectivos, etc." (5).

Las PV ofrecen problemas que afectan el cambio semántico y la gramaticalización, por una parte; y la relación sintáctica entre los elementos que las forman, por otra. En términos generales, la PV corresponde a la unión de dos o más formas verbales, las cuales funcionan como una unidad y están constituidas por: un verbo auxiliar conjugado (es decir, que está en forma personal); un elemento de enlace (preposición, conjunción) que puede aparecer o no: tengo que comer, iba a gritar, debes ( $\varnothing$ ) estudiar, y el verbo principal que va en forma no personal: infinitivo, gerundio o participio.

Las PV de cada lengua permiten marcar algunas características de la acción que no pueden ser expresadas por las formas simples o compuestas del verbo. Existen básicamente dos tipos: las modales y las aspectuales.

\section{Perífrasis modales}

Las perífrasis modales sirven para expresar la actitud del hablante ante la acción. Indican que el hablante interpretará la acción, bien como una obligación o como una posibilidad. Veamos algunos casos de obligación:
Deber + infinitivo:
debes leer concentrado.
Tener que + infinitivo:
Haber que + infinitivo: tiene que llegar temprano.
Haber de + infinitivo: hay que estudiar para el examen. has de estudiar por la tarde.

Así mismo, observemos ejemplos de posibilidad:

Puede que + subjuntivo: puede que llegue muy tarde.

Poder + infinitivo: $\quad$ él puede llegar pronto.

Ejemplos de duda o aproximación:

Deber de + infinitivo: deben de ser las nueve.

Venir a + infinitivo: $\quad$ esto viene a costar treinta soles. 


\section{Perífrasis aspectuales}

Las perífrasis aspectuales indican el modo en que es percibida la acción del hablante; a esto se le denomina aspecto y existe el aspecto imperfectivo y el perfectivo. El aspecto imperfectivo muestra que la acción no tiene límites temporales: al hablante no le preocupa indicar si la acción ha comenzado o si va a terminar, lo importante es indicar la acción en su propia duración; mientras que el aspecto perfectivo marca si la acción ha comenzado, si está a punto de comenzar, si está para acabar, etc.

\section{*Aspecto imperfectivo}

El aspecto imperfectivo presenta tres formas: durativo, durativo retrospectivo y durativo prospectivo.

Durativo: indica una acción que se está desarrollando.

Estar + gerundio: estábamos leyendo la revista. Andar + gerundio: anda diciendo que le has gritado. Seguir/continuar + gerundio: ella sigue corriendo en la playa. Llevar + gerundio: llevo escribiendo dos horas. Ir + gerundio: vamos perdiendo uno a cero.

Durativo retrospectivo: retoma la acción desde el pasado y la hace continuar en el presente: llevo, vengo estudiando.

Durativo prospectivo: arranca la acción desde el presente y la prolonga hacia el futuro: voy leyendo y tú vas copiando.

\section{*Aspecto perfectivo}

El aspecto perfectivo presenta las siguientes formas: ingresivo, incoativo, resultativo, reiterativo, terminativo y habitual.

Ingresivo: indica una acción que está a punto de empezar.

Estar a punto de + infinitivo: la película está a punto de empezar. Ir a + infinitivo: va a caer una fuerte lluvia. Estar para + infinitivo: está para llover.

Incoativo: indica una acción que empieza en términos de progresión.

Echarse a + infinitivo: se echó a llorar. Romper a + infinitivo: rompió a llorar. Ponerse a + infinitivo: se puso a llorar. Empezar/comenzar a + infinitivo: empezó a reír.

Resultativo: considera la acción como resultado.

Estar + participio: está hecho desde ayer. Llevar + participio: lleva hecho desde la semana pasada.

Reiterativo: repite la acción una vez.

Tener + participio: te tengo dicho que lo dejes aquí. Volver a + infinitivo: te vuelvo a decir que lo dejes aquí. Dejar + participio: he dejado dicho que te lo den. 
Terminativo: señala el punto justo de conclusión de una acción.

Dejar de + infinitivo: dejé de fumar hace dos meses. Acabar de + infinitivo: acabo de entregárselo a María.

Habitual: repiten la acción varias veces.

Soler + infinitivo: suelo estudiar.

\section{Clasificación de las perífrasis verbales}

De acuerdo con Roca Pons (4) las PV del español se clasifican en: a) perífrasis con participio; b) perífrasis con gerundio, y c) perífrasis con infinitivo.

\section{* Perífrasis con participio}

En primer lugar, hay que señalar la importancia de las nociones de voz, aspecto y tiempo en relación con la aparición o finalidad actual de esta clase de perífrasis. La clasificación de Roca Pons se basa no en el hecho de tener una perífrasis de carácter activo o pasivo, perfectivo o imperfectivo, sino en el de haber sido creada para expresar una determinada modalidad de voz, aspecto, etc., o para que tenga dicha finalidad en la lengua actual. Dicho esto, se puede establecer una primera clasificación:

- Verbos transitivos (tener)

En relación con la idea de posesión

Con verbos imperfectivos. Ejemplo: Aún tiene la casa vigilada.

Con verbos perfectivos

Con participio imperfectivo o que admite esta interpretación. Ejemplo:

¿Pero cómo tienen sin cerrar esta condenada puerta?

Con participio perfectivo. Ejemplo: Tengo concedido el permiso.

Sin relación con la idea de posesión

Con verbos imperfectivos

Con idea de estado en el objeto. Ejemplo: El temor me tenía trabado el entendimiento.

Sin verdadera idea de estado en el objeto. Ejemplo: Se ha habituado a usarlo.

Con verbos perfectivos

Participio imperfectivo o que admite esta interpretación. Ejemplo: Me tienen continuamente afanado.

Participio perfectivo. Ejemplo: Me tienes cansado de escucharte.

- Verbos intransitivos (estar) con participio

Con idea de lugar

Participio imperfectivo o que admite esta interpretación. Ejemplo: Estaban huidos en Inglaterra. 
Participio perfectivo. Ejemplo: Mi mente descubre la naturaleza común de hombre que está realizada en todos ellos.

Sin idea de lugar

Con verbos imperfectivos

Con valor pasivo. Ejemplo: La música clásica estaba sostenida por los grandes maestros italianos y alemanes de aquella generación.

Con valor activo. Ejemplo: Sandro, estás muy atrevido.

Con verbos perfectivos

Participio imperfectivo. Ejemplo: Yo era enamorado de una vendedora en abril.

Participio imperfectivo o perfectivo

Valor pasivo. Ejemplo: Que estamos desterrados de Canadá.

Valor activo. Ejemplo: Porque estoy de ganancia y soy enamorado.

Participio perfectivo

Valor pasivo. Ejemplo: Aunque creo que no está acabado de hacer.

Valor activo. Ejemplo: Por Dios, que estoy corrido.

\section{* Perífrasis con gerundio}

Roca Pons (4) clasifica las perífrasis con gerundio por el aspecto y considera este criterio en sentido amplio, ya que por él se diferencian y tienen carácter propio. También debe tenerse en cuenta cada uno de los auxiliares empleados, con su especial y característica aportación significativa y aspectual a la nueva unidad construida con gerundio, que constituye el soporte para otros valores. Así tenemos:

Valor inceptivo: acción o proceso incipiente. Ejemplo: Ya va amaneciendo.

Valor incoativo: cambio gradual hacia un nuevo estado aumentando o disminuyendo más o menos gradualmente y en algún aspecto, el estado o situación ya existentes. Ejemplo: Va creciendo.

Valor continuativo: continuidad o persistencia de un estado o situación. Ejemplo: Va estudiando.

Valor iterativo: se presenta con algunos verbos de acción momentánea, no susceptibles de consideración durativa o imperfectiva. Ejemplo: Van disparando.

Valor frecuentativo: el más importante es el que aparece con 'soler + infinitivo'. Ejemplo: Suele cantar en las mañanas.

Valor intensivo: acompaña el simple imperfectivo o durativo u otros valores en el uso de 'andar + gerundio'. Ejemplo: Andar buscando. 
Principales auxiliares empleados en el uso de perífrasis con gerundio

\begin{tabular}{|c|c|}
\hline Auxiliares & Estar, quedar, ir, andar y venir \\
\hline Semiauxiliares & Seguir, continuar \\
\hline
\end{tabular}

\section{* Perífrasis con infinitivo}

A diferencia de las perífrasis con gerundio, las que se forman con el infinitivo son expresiones motivadas por el modo y el tiempo preferentemente, al lado de otras en la que la razón decisiva es el aspecto.

Aspecto ingresivo

Si empezamos por el aspecto, podemos nombrar algunas clases. Algunos ejemplos que guardan relación con el aspecto ingresivo son:

$$
\begin{array}{lll}
\text { 'echar a + infinitivo' }: & \text { echar a andar } \\
\text { 'lanzarse a + infinitivo' : } & \text { lanzarse a pelear } \\
\text { 'echarse a + infinitivo' : } & \text { echarse a temblar } \\
\text { 'arrojarse a + infinitivo': } & \text { arrojarse a decir } \\
\text { 'romper a + infinitivo' : } & \text { romper a llover } \\
\text { 'darse a + infinitivo' : } & \text { darse a buscar } \\
\text { 'meterse a + infinitivo' : } & \text { meterse a guisar } \\
\text { 'ponerse a + infinitivo' : } & \text { ponerse a comer } \\
\text { 'empezar a + infinitivo' : } & \text { empezar a llorar }
\end{array}
$$

\section{Modos}

Si tomamos en cuenta el modo, podemos mencionar los siguientes:

- Modo de acción factitivo: se obtiene con hacer, dejar y mandar. Ejemplo: Hizo construir una casa.

- Modo reiterativo: se presenta con volver, tornar. Ejemplo: Hizo volver a pintar la casa.

- Modo frecuentativo: con 'soler + infinitivo'. Ejemplo: Suele venir cada día.

A continuación se presenta una lista en donde se distinguen algunos caracteres modales:

De necesidad:

$\begin{array}{lll}\text { Haber de, que + infinitivo' } & : & \text { has de aconsejarle; } \\ \text { tener de, que + infinitivo' } & : & \text { tiene que acabar mal; } \\ \text { deber + infinitivo' } & : & \text { debe llegar pronto; } \\ \text { poder } & : & \text { puedes acabarlo; } \\ \text { saber } & : & \text { sé tocar el piano. }\end{array}$


De orden o mandato:

$$
\begin{aligned}
& \text { Ir a + infinitivo' : } \quad \text { vas a terminarlo ahora mismo; } \\
& \text { querer + infinitivo' : ¿quieres dármelo?; } \\
& \text { poder + infinitivo' : } \quad \text { puedes seguir. }
\end{aligned}
$$

De volición

Las PV de la lengua española abordadas desde el punto de vista de Roca Pons tienen como objeto a la expresión de un estado con exclusión de la idea de movimiento. Con la unión de los verbos auxiliares a los que hemos hecho referencia y el participio así como el adjetivo y construcciones equivalentes se obtiene la expresión de un estado considerado como una situación pasiva en la que se halla el sujeto (estado alcanzado o permanente). El estado alcanzado es la modalidad estativa más importante.

La importancia del aspecto verbal en relación con las perífrasis estudiadas es evidente, las cuales son aptas para la expresión de un aspecto de perfecto en el sentido de estado alcanzado, aunque no es esta su única función, según se ha indicado.

El concepto de voz tiene importancia especial en relación con el empleo de los verbos auxiliares intransitivos, pues el estado puede ser consecuencia de un proceso pasivo, medio o de una acción reflexiva. Sin embargo, se ha partido de la dualidad fundamental activa-pasiva en el participio. Con verbos imperfectivos se da la idea de acción o proceso pasivo junto con la de estado, de acuerdo con el carácter activo o pasivo del participio.

\section{Perífrasis verbales aspectuales}

El verdadero valor de los verbos estudiados se precisa mucho mejor si se compara con el de otros auxiliares del mismo tipo. El trabajo de Dietrich (6) se centra en el estudio de las perífrasis verbales de categorías aspectuales, presentado inicialmente por Coseriu en un sistema funcional coherente. Tal es el caso del español, cuyas perífrasis verbales aspectuales presentamos:

'ir a + infinitivo', 'estar + gerundio', 'ir, andar, venir, llevar + gerundio', 'ir, andar, seguir + participio', 'seguir, continuar, permanecer + gerundio', 'quedar (se) + gerundio', 'tomar, coger, agarrar, ir, saltar' (Puerto Rico, España); 'llegar' (Chile) en construcción copulativa, 'estar para, estar por + infinitivo', 'salir + gerundio', 'ponerse a ,echarse a, romper a, coger a, entrar, dar a (en desuso); agarrar a (en desuso en España); soltarse al, largarse a, pasar a, empezar a, 
comenzar a + infinitivo', 'continuar a + infinitivo', 'acabar de + infinitivo', 'empezar, continuar por, comenzar por, terminar por, concluir por + infinitivo', 'llegar a, ir a, venir + gerundio', 'ir, venir en construcción copulativa (fue y dijo)', 'volver a, tornar a + infinitivo, etc.'

\section{Perífrasis verbales según Mihaela Topor}

Mihaela Topor (7), sobre la base de trabajos y estudios de PV, plantea una evaluación de criterios que conduce a la clasificación de verbos auxiliares de infinitivo y de gerundio con la clase A que tradicionalmente se han reconocido como perifrásticos: deber, poder, soler, acabar, ir, seguir, venir; y verbos supuestamente reconocidos como auxiliares perifrásticos que corresponden a la clase B: aceptar, necesitar, osar, pensar, pretender, querer, saber, comenzar. Los verbos de la clase B son considerados verbos que se enmarcan en el contexto de casos de auxiliares dudosos. Los criterios de evaluación que considera Topor son semánticos, morfológicos, sintácticos y sintáctico-semánticos. Seguidamente se hará referencia al criterio sintáctico en términos de aplicación y análisis de los datos.

En el marco del criterio semántico, Topor plantea un evento unitario sustentado en la descripción básica de verbos auxiliares: "Según este criterio, una PV está formada por dos verbos que constituyen un solo núcleo verbal desde el punto de vista semántico" (7, p. 52). Así mismo, considera las restricciones de selección que se relaciona con el hecho de que los verbos auxiliares están impedidos para seleccionar sujetos y complementos. Este criterio presenta problemas, fundamentalmente porque algunas de las clases de verbos no presentan restricciones y funcionan como PV. Finalmente, dentro del criterio semántico sostiene la doble funcionalidad del verbo auxiliar, concepto que se sustenta en que un auxiliar perifrástico puede actuar tanto como auxiliar propiamente dicho o como verbo predicativo, concepto que Topor $(7$, p. 54$)$ cuestiona este criterio y consecuentemente lo invalida.

Según el criterio morfológico, los verbos poder y venir presentan un paradigma completo; sin embargo, son funcionalmente auxiliares, hecho que lleva a la autora a observar la fundamentación de este criterio: “...son verbos auxiliares los que no tienen el paradigma verbal completo" (7, p. 55).

Los criterios sintácticos adquieren mayor importancia, pues muestran la unidad del conjunto verbal y están sometidos a criterios mucho más rigurosos entre los que destacan la conmutación, la interrogativa, la enfatización, la promoción de clíticos y la reducción del grupo perifrástico a una forma verbal conjugada del verbo principal.

La prueba de conmutación se refiere a casos de impedimento de permutación en una PV del verbo en infinitivo con un sintagma nominal (SN), el verbo 
en gerundio por el adverbio, un pronombre o una proposición por el elemento conjuntivo 'que'. Empero, no hace falta que se realicen todas las conmutaciones posibles pues pese a existir casos en los que la conmutación es posible, se considera válido y pertinente debido a la poca frecuencia de dichos casos.

Según la autora, la interrogativa se refiere a que una PV no permite formular preguntas, es decir, no es posible interrogar acerca del infinitivo con el pronombre interrogativo 'qué' ni del gerundio con el pronombre interrogativo 'cómo', hecho que sí puede producirse en construcciones no perifrásticas.

La enfatización corresponde a PV que no posibilitan la transformación con 'lo que...es' ni 'como... es'; para el primer caso corresponderán las PV de infinitivo; para el segundo, las PV de gerundio.

La prueba de la promoción de clíticos se refiere al hecho de que estos pronombres pueden anteponerse al conjunto verbal, criterio que sustenta el carácter unitario de la estructura perifrástica.

\section{Análisis y discusión}

En términos generales, el procedimiento principal que utilizan las lenguas románicas para ampliar y modificar sus sistemas verbales es la creación de perífrasis. Gracias a sus elementos auxiliares (infinitivo, gerundio, participio y verbos auxiliares), la conjugación puede renovar sus formas desgastadas por el uso y crear otras nuevas, más o menos compuestas o perifrásticas que poco a poco van consolidándose y reorganizando sus sistemas. El grado de consolidación de estos sistemas perifrásticos puede ser muy diverso y los criterios para determinarlos son difíciles y relativos. Se trata de las formaciones más vivas del lenguaje, en continua creación y evolución, y no es posible establecer entre ellas fronteras ni límites fijos, más aún si se toman en cuenta las características particulares de las variedades dialectales en contacto con lenguas amerindias (amazónicas).

A continuación se presenta, en primer lugar, las diferentes estructuras perifrásticas que se producen en el castellano de los indígenas bilinguies de la selva central del Perú.

Las perífrasis verbales de cada lengua permiten marcar algunas características de la acción que no pueden ser expresadas por las formas simples o compuestas del verbo. Existen básicamente dos tipos: modales y aspectuales. En el caso del castellano de los indígenas bilinguies de la selva central del Perú, se puede indicar en términos de mayor a menor frecuencia de uso las siguientes estructuras perifrásticas. En el caso de los modales, debemos señalar que la producción alcanza al uso de dos estructuras diferentes, es decir, 'deber + infinitivo' y 'poder + infinitivo'; el segundo tiene apenas tres apariciones frente a 13 del primero. 


\section{Pedro Falcón Ccenta}

\section{Construcciones perifrásticas modales}

Los ejemplos consignados y cuantificados en el cuadro 1 corresponden a construcciones perifrásticas modales de obligación en la que el hablante interpreta una acción, ya sea con el sentido de obligatoriedad o como posibilidad, tal como se observa en los ejemplos del 3 al 13, centralmente de obligatoriedad y en los ejemplos 1 y 2 , de posibilidad, cuya estructura responde a verbos en modo subjuntivo en el primer caso. Este tipo de PV indica el carácter obligativo que evidencian las entradas en las que intervienen verbos como 'tener, deber, haber + infinitivo' (...deben tener limpio, deben barrer esto). Con 'haber' la frase parece adquirir un carácter menos imperativo que con 'tener' (... cuando uno quiere...hay que producir).

En términos cuantitativos, la producción de construcciones perifrásticas modales en todo el corpus revisado se reduce a 16 entradas, de las cuales 13 corresponden a perífrasis verbales que expresan obligación, cuya estructura es 'deber + verbo infinitivo'; y tres cuyas formas expresan posibilidad o duda. La estructura única producida es 'poder + infinitivo'. Las entradas que corresponden a modales de obligación atenuada son producidas por mujeres, mientras que las que expresan modales con un matiz de menos obligación y duda o posibilidad son producidas mayormente por varones.

Cuadro 1. Distribución de construcciones perifrásticas modales

\begin{tabular}{|c|c|c|}
\hline Perífrasis verbales & Apariciones & Porcentaje \\
\hline 'Poder + infinitivo + (enclítico)' & 3 & $18,75 \%$ \\
\hline $\begin{array}{c}\text { 'Deber + infinitivo' } \\
\text { 'Tener que + infinitivo' } \\
\text { 'Haber que + infinitivo' }\end{array}$ & 13 & $81,25 \%$ \\
\hline \multicolumn{2}{|c|}{ Variables: Grado de instrucción, género, edad } \\
\hline
\end{tabular}

Ejemplos:

'Poder + infinitivo'

1. ...proteger a mi familia con lo... con lo poco que... que se puede... pueda ganar... (Gerardo, CN Chembo). ${ }^{1}$

2. ....solo me queda un año más para terminar mi colegio y así poder prepararme en la academia (...) (Rosa, San Antonio de Sonomoro).

1 Los datos consignados entre paréntesis corresponden a los nombres de los colaboradores y comunidad nativa a la que pertenecen 
'Deber + infinitivo'

3. ....esto no debe estar así, las calles deben tener limpio, deben barrer esto (Rosa, San Antonio de Sonomoro).

4. ...hay pastores que este... son jóvenes que les incentivan... para el buen camino que deben seguir... (Yolanda Marco, Santa Clara).

'Tener que + infinitivo'

5. ...sí, o sea que... al día siguiente ya se le solea, no es como el café que tiene que cosechar... tiene que esperar de un día para otro para lavar el café... (Mirta Chimanca, San Antonio de Sonomoro).

8. ...cada rato tienes que levantar a cambiar... (Jéssica, Santa Clara).

9. ....sí, eso se tienen que hacer antes de... (Yanan Curi, Santa Clara).

'Haber que + infinitivo'

12. ...cuando uno quiere... hay que producir... (Fermín Marco, Santa Clara).

13. ...eso se llama remedio obenki, acá hay variedad hay que buscar para ver cuál es mejor (José Luis, San Antonio de Sonomoro).

Los ejemplos mencionados son PV, pues conceptualmente constituyen una unidad verbal desde el punto de vista semántico. Siguiendo a Topor, se diría que los verbos poder y venir presentan el paradigma completo, ya que cumplen las pruebas que muestran su carácter auxiliar.

En cuanto a las variables extralinguísticas, se señala en primer lugar que los datos recopilados presentan un número reducido de este tipo de estructuras. Ello implica poca variedad en la combinación de verbos y también que las mujeres sistemáticamente, tal vez como reflejo de la lengua materna, hacen uso de formas infinitivas con los auxiliares no conjugados con un matiz de obligación; sin embargo, en los hombres estas formas aparecen en pocos casos, pero con un matiz de poca obligación. Ejemplo: “...hay que producir”.

Así mismo, las mujeres con menor instrucción estructuran PV modales con enclíticos. Ejemplo: “... así poder prepararme”.

\section{Construcciones perifrásticas aspectuales}

En el caso de los aspectuales, la producción de variedades estructurales es mayor respecto de los modales, pues registra seis estructuras diferentes. El de mayor aparición es la forma 'estar + gerundio' con 116 apariciones; 'ir + (prep) infinitivo' con 67 apariciones; luego 'comenzar a + infinitivo' con 6; y 'estar por + infinitivo' con una aparición en el discurso del hablante bilingüie indígena.

Se señala que las construcciones perifrásticas son simples, es decir, no hay representaciones complejas; las más simples son las producidas por las mujeres, con menor grado de instrucción que los hombres.

Letras 81 (116), 2010 
Cuadro 2. Distribución de construcciones perifrásticas aspectuales

\begin{tabular}{|c|c|c|}
\hline Perífrasis verbales & Apariciones & Porcentaje \\
\hline 'Ir (preposición a) + infinitivo' & 67 & $35,26 \%$ \\
\hline 'Estar + gerundio' & 116 & $61,05 \%$ \\
\hline 'Comenzar (a) + infinitivo' & 6 & $3,15 \%$ \\
\hline 'Estar por + infinitivo' & 1 & $0,52 \%$ \\
\hline
\end{tabular}

Ejemplos:

'Ir (a) + infinitivo'

14. ....ahora por tu culpa vas a ir a trabajar (José Luis, San Antonio de Sonomoro).

15. ...ya pues se quedó he escuchado tu mamá va a venir... allá (José Luis, San Antonio de Sonomoro).

16. Mi esposa vive acá, vamos hacer recreación (Marco Gómez, comunidad Bocacheni).

17. ... es artesanía... esto va crecer poco o a poco dependiendo de la economía (Marco Gómez, comunidad Bocacheni).

18. ...Ah ya, hasta ahí ya voy volver, ya pe, ya (Olga Sánchez, Santa Clara).

19. ...bueno ahora voy a bañar, recién he llegado de la chacra recién (Julio Pizarro, Santa Clara).

20. ...voy lavar ropa (Jéssica, Santa Clara).

21. ....ahí matamos animales del monte, chancho, samani... eso ustedes qué van a conocer (Emilio Nancuya, Santa Clara).

22. ...así... el profesor acá solamente enseñan castellano, pero este año creo que vamos a pedir un profesor bilingüe ya... (Emilio Nancuya, Santa Clara).

23. ...ha ido a tirar parral... (Rosa Pari, Santa Clara).

51. ...no, voy a quedarme a hacer collares (Rosa Pari, Santa Clara).

24. ...iba a llegar este mes, abril, pa que lo vacune (Daniel, Río Bertha).

25. ....hí van a poner... (Elisa, Bocacheni).

26. Llévala pe, vamos pescar, vamos a ver (Manuel, Bocacheni).

27. ...no, no, recién estamos este...va a ser como un albergue (Pablo Cáceres, San Antonio de Sonomoro).

28. ...aguajero en esas chozas por donde va a pasar la flecha... (Mario Flores, San Antonio de Sonomoro).

29. ...ya voy cumplir nueve (Raquel, Santa Clara). 
30. ...vamos aumentar casitas que faltan por este lado, vamos a construir casas (Julio Pizarro, Santa Clara).

31. ...ah si, van a hacer siempre dentro del año (Olga Sánchez, Santa Clara).

Cabe mencionar que en muchos casos se produce la elisión de la preposición 'a' como en "... ah ya, hasta ahí ya voy volver..., voy lavar ropa..., ... ya van venir seguro...". El proceso mencionado se observa en gran medida en la producción de hombres y mujeres que tienen bajo grado de instrucción, aunque con mayor énfasis en las mujeres tanto ashaninka como nomatsiguenga; asumimos que se debe a la menor movilidad e interacción que tienen con pobladores hispanohablantes, respecto de los hombres. Debemos señalar, además, que estas formas perifrásticas particulares obedecen a la influencia estructural de la lengua materna, pues como la lengua ashaninka es fundamentalmente aglutinante sufijal, no presenta estos nexos preposicionales. Así, por ejemplo, en la oración nonkibero nochenko \{no - n- kibe - ro no-chenko\} 'yo voy lavar mi pantalón', el prefijo no- 'yo', -n- 'futuro' y -kib- (kib-aantsi) 'lavar'- e- 'futuro' -ro 'objeto directo' no presenta ningún elemento preposicional ni morfológico ni sintáctico. Por ello, consideramos que estas PV forman parte de la adquisición de lengua castellana, que en determinadas comunidades nativas más conservadoras y en las zonas hispanohablantes circundantes a ellas parece cobrar fuerza este tipo de construcciones.

Cuadro 3. Elisión de la preposición

\begin{tabular}{|c|}
\hline Estructura perifrástica \\
\hline 'Ir + preposición + verbo infinitivo' \\
\hline 'Verbo conjugado $+\phi+$ verbo infinitivo' \\
\hline Variables: grado de instrucción, influencia de lengua materna, género, edad. \\
\hline
\end{tabular}

'Estar por + infinitivo'

32. ... estaban por llegar y ahí se desaparecieron, nunca más han visto... han ido helicóptero... la caja de el helicóptero casi la cae también (Emilio Nancuya, Santa Clara).

'Comenzar a + infinitivo'

33. ... o sea hay tiempos que también pe no hay una temporada ...por ejemplo, en este tiempo ya baja; de setiembre, agosto ya empieza a bajar hasta octubre, noviembre ya. ... (Yolanda Marco, Santa Clara).

34. ... ya pasado todo esto los lideres tomaron nuevamente reactiva a la comunidad, en esos tiempos comenzó a aumentar la población y poco a 
poco iban mejorando todas sus cosas (Rojas Chimaca, San Antonio de Sonomoro).

35. ....Triste, ya y comenzó a llover... (Emilio Nancuya, Santa Clara).

36. .... ah, por decir, en esta construcción las mujeres comienzan a doblar las hojas, porque la hoja viene así tendido como una palmera que se tiene que doblar de un lado para que quede como una tabla, eso hacen las mujeres ; los varones comienzan a excavar, comienzan a armar, otros van parando el palo, otros van preparando el palo (Mario Flores, San Antonio de Sonomoro).

37. ...y eso según que cuando esa hormiga cuando está en la placenta dice comienza tener heridas y cuando ya lo escarban ahí encuentra hormigas, todo... (Mirta Chimanca, San Antonio de Sonomoro).

'Estar + gerundio'

38. Está haciendo sus collares.

39. ... sí... mi hijo está estudiando en Lima (Daniel, comunidad Río Bertha).

40. Sí, si yo estuve haciendo en mi casa mi trabajo (Hortensia, Río Bertha).

41. ... o sea, cuando hay un compromiso, están haciendo su concurso (Hortensia, Río Bertha)

42. ... estoy esperando veterinaria, iba a llegar este mes, abril, pa que lo vacune (Daniel, comunidad Río Bertha).

43. ... Con este gobierno que estamos viendo ahora este... no es tanto favorable para... (Pablo Cáceres, San Antonio de Sonomoro).

143. ... su esposo está trabajando (Julio Pizarro, Santa Clara).

44. ... hierba del monte para que no sea hospitalizada está dando a luz hay remedios que traemos del monte (Fermín Marco, Santa Clara).

45. ... sabes que cuando uno está menstruando no debes pasar por un charcado en que haya arco iris porque si tú estás menstruando y pasas... (Juana, San Antonio de Sonomoro).

46. .... no, sí hay mujeres también que curan... aquí la señora que está vistiendo la cushma azul ese sabe curar... y ustedes sabe, como estoy diciendo es nomachiguenga, no habla bien el castellano ... (Emilio Nancuya, Santa Clara).

47. ... el dulce es cuando recién está fresco, lo estás preparando es dulce... rico es y cuando está así fuerte es ya pa huasquiarse (Rosa Pari, Santa Clara).

Las estructuras más productivas generadas por los hablantes indígenas bilinguies corresponden a las forma 'estar + gerundio' con 116 apariciones, 'ir + prep $(\varnothing)$ + infinitivo’ que alcanza una producción de 67 entradas; luego se encuentra la forma 'comenzar (empezar) a + infinitivo' con 6 apariciones y 'estar 
por + infinitivo' con una aparición. Desde el punto de vista funcional, las expresiones perifrásticas más productivas generadas por los indígenas bilinguies amazónicos de la selva central del Perú son aquellas de contenido gramatical propio que no tiene formas alternativas de expresión, así tenemos: “...vamos a trabajar, su hijo tenía ocho, diez, dos añitos no más, claro va acompañar a su papá; ... sí, siempre ahora que va a llegar el invierno va a ser sombra”.

Así mismo, si bien existen tiempos compuestos de la conjugación llevadas a un extremo de cohesión, existen combinaciones formadas por el auxiliar y el participio en las que este conserva cierta independencia; sin embargo, de acuerdo con el corpus recogido, las construcciones perifrásticas responden a las llamadas durativas, en las que la forma verbal es el gerundio acompañado del auxiliar 'estar'. Ejemplos:

“... sí... mi hijo está estudiando en Lima”.

“...o sea, cuando hay un compromiso, están haciendo su concurso".

"...después la araña pe le habla pe y se pone nerviosa y como estaba tejiendo pe su telaraña y voltea y qué cosa quiere...”

También hay construcciones perifrásticas que indican el modo en que es percibida la acción del hablante, es decir, construcciones en las que el hablante expresa enunciados sin tomar en cuenta si la acción ha comenzado o va a terminar (imperfectivo) y tampoco marca los límites de la acción (perfectivo).

En términos generales podemos decir que tanto las construcciones perifrásticas modales como aspectuales del castellano extraídas de la producción de los colaboradores ashaninka y nomatsiguenga de la familia linguística arawak responden a los criterios sintácticos planteados por Topor.

Según el criterio de conmutación (7), si a la oración 'debes estudiar más', se le aplica la prueba de reconocimiento "Debes más estudio (SN), es decir, si se conmuta el verbo estudiar por el SN estudio, entonces la oración pierde su condición de gramaticalidad. Sucede lo mismo en el caso del gerundio al conmutar el verbo por el adverbio 'así'.

Según diferentes estudios, esta forma perifrástica es la más usada, hecho que ocurre entre los hablantes bilinguies ashaninka-castellano y nomatsiguenga-castellano. Siguiendo a Yllera, hay mayor recurrencia en el uso de la perífrasis de gerundio; esta presenta una visión de la acción en su desarrollo, una visión de la acción en curso, que coincide con lapso temporal (breve o extenso) situado en el presente, pasado o futuro, según el tiempo de estar aunque proceda de un momento anterior y pueda prolongarse posteriormente a menos que se acompañe de adverbiales que delimiten su duración (8).

En el estudio, podemos advertir que mayoritariamente las construcciones perifrásticas con gerundio están conjugadas en tiempo presente, en primera y tercera persona; así mismo, algunos casos están relacionados con el grado de 
instrucción y la mayor exposición al castellano que utilizan el tiempo pasado. Ejemplos:

'poder + infinitivo'

48. ... proteger a mi familia con lo... con lo poco que... que se puede... pueda ganar... (Gerardo, Chembo).

49. ... solo me queda un año más para terminar mi colegio y así poder prepararme en la academia... (Rosa, Sonomoro).

'deber + infinitivo'

50. ... hay pastores que este... son jóvenes que les incentivan... para el buen camino que deben seguir... (Yolanda Marco, C.N Santa Clara).

'estar + gerundio'

51. Está haciendo sus collares.

52. ...sí... mi hijo está estudiando en Lima (Daniel, comunidad Río Bertha).

53. Si, sí, yo estuve haciendo en mi casa mi trabajo (Hortensia, comunidad Río Bertha).

Se deben mencionar además las estructuras de PV con clíticos. Sobre este punto, Topor señala que se considera PV si el clítico puede ser antepuesto, lo que evidencia su unidad estructural. Ejemplos:

- La chica está alimentándose à La chica se está alimentado.

- El profesor está indicándole lo que... à El profesor le está indicando lo...; sin embargo, hay casos que no responden a la aplicación del criterio antes mencionado. Ejemplos:

* ...están dialogándose con su mujer... à *se están dialogando con su mujer...

* ...empiezan discutirse... à "se empiezan discutir..

Se debe señalar que este tipo de construcciones, que no están consignadas en las entradas numeradas, son producidas por mujeres con bajo grado de instrucción.

Si bien la gama de estructuras perifrásticas usadas en el castellano de los indígenas bilinguies amazónicos de la selva central del Perú cuantitativamente es recurrente en estructuras muy limitadas en términos de frecuencia, las más productivas se reducen a las referidas líneas arriba, vale decir, 'estar + gerundio e ir + infinitivo'. No hay producción de formas con el participio.

En cuanto a las variables inherentes y adscritas se debe señalar que en relación con el sexo se observa una relativa riqueza de de estructuras perifrásticas dentro del marco de la variedad producida por la población; respecto a la edad, relacionada con la variable escolaridad, se advierte también un uso más variado y el mayor porcentaje es producido por varones. 


\section{Conclusiones}

4.1. Tomando en cuenta la riqueza del castellano en construcciones perifrásticas, que dispone en sus numerosas frases verbales de un instrumento productivo para la expresión de las diversas modalidades de la acción verbal tanto en su proceso de auxiliaridad como de gramaticalización, se debe señalar que la producción perifrástica del castellano de los indígenas bilinguies de la selva central del Perú es más bien limitada en cuanto a variedad y complejidad. Centra su productividad y frecuencia en las formas 'ir + prep $(\varnothing)+$ infinitivo' o 'estar + gerundio' que son formas de mayor frecuencia en el castellano en general.

4.2. El dinamismo de la lengua permite que se abandone una serie de categorías tradicionales para ir creando otras nuevas que respondan a las necesidades comunicativas; empero, ese dinamismo esperado no ocurre en estos grupos bilinguies, ya que restringen sus construcciones perifrásticas a la serie de categorías tradicionales simples.

4.3. El comportamiento perifrástico en esta variedad permite observar una estrecha vinculación entre la auxiliaridad, que se constituye en un proceso unificador entre dos elementos, y la unidad verbal derivada. Los efectos de este proceso de auxiliaridad se expresan en las fusiones sintácticas y semánticas de las perífrasis verbales, así como en el proceso de gramaticalización que sin duda abre la posibilidad de un estudio más detenido y extenso.

4.4. Las perífrasis verbales no parecen ganar mucho terreno en esta parte de la Amazonía, por lo menos en términos de mayor variedad y riqueza como ocurre en los sectores populares o grupos menos favorecidos, tal vez se deba al uso del castellano como segunda lengua en todos nuestros entrevistados; consecuentemente, podemos decir que hay un uso relativamente más variado y más complejo en hablantes bilingüies con mayor grado de instrucción.

4.5. Cuantitativamente y cualitativamente las variables sociales (edad, grado de instrucción y género) condicionan la producción de las construcciones perifrásticas, pues la producción cuantitativa y relativamente variada está sujeta a cada una de las variables consignadas.

4.6. Las perífrasis verbales más recurrentes cuantitativamente corresponden a las formas aspectuales 'estar + gerundio' e 'ir (preposición) + infinitivo (Rosa CN. Sonomoro). En este último caso, en gran proporción se elide la preposición en estructuras en las que es obligatoria. Ocurre incidentemente cuando está relacionada con las variables de género y grado de instrucción. 
Pedro Falcón Ccenta

\section{Referencias bibliográficas}

COSERIU, Eugenio (1968). "El aspecto verbal perifrástico en griego antiguo”. En: Actas del III Congreso Español de Estudios Clásicos. Coloquio de Estudios Estructurales sobre Lenguas Clásicas. Madrid.

DIETRICH, W. (1983). El aspecto verbal perifrástico en las lenguas románicas. Madrid, Ed. Gredos.

HERNANZ, María Luisa (1980). Las perífrasis verbales del infinitivo en español. Hacia una posible solución transformacional. Madrid, Arco Libros.

SECO, Manuel (2002). Gramática esencial del español. Madrid, Ed. Espasa Calpe S.A.

ROCA PONS, José (1958). "Estudios sobre perífrasis verbales del español”. En: Revista de Filología Española. Anexo LXVII.

ROCA PONS, José (1967). Estudios sobre perífrasis verbal del español. Madrid.

TOPOR, Mihaela (2005). "Criterios identificadores de las perífrasis verbales en el español”. En: Sintagma; Revista de lingüística 17; pp. 51-69.

YLLERA, Alicia (1999). "Las perífrasis verbales de gerundio y participio". En Ignacio Bosque y Violeta Demonte (editores). Gramática descriptiva de la lengua española. Madrid: Ed. Espasa Calpe; Tomo II; pp. 3391-3441. 